\title{
NOS BASTIDORES DA TELENOVELA ${ }^{1}$
}

\begin{abstract}
A telenovela firmou-se a partir da década de 70, com a vinda para a televisão de grandes nomes do cinema e do teatro. Estes artistas criaram uma linguagem própria e um produto consagrado pelo público. Hoje eles trabalham para manter a qualidade temática e expressiva da telenovela, teimando em falar das coisas e das gentes do Brasil.
\end{abstract}

A telenovela está atravessando um impasse no Brasil, um momento difícil, um momento que talvez seja um divisor de águas. Alguma coisa está para acontecer, a gente não sabe o que é, mas alguma coisa está mudando. Eu espero que não seja para pior, pior no sentido de se considerar que telenovela é só um gênero de telecomunicação, e não mais uma manifestação artística como pretendíamos. Parece que essa segunda hipótese - da telenovela como gênero de manifestação artística está colocada hoje num absoluto segundo plano.

A preocupação das emissoras de televisão está centrada mais na comunicação do que propriamente na qualidade artística do produto. Isso foi muito diferente no passado. A telenovela tinha ambições estéticas. Atualmente os números são mais importantes, a audiência, o impacto que possa provocar no grande público, através de temática mais fácil e menos ambiciosa.

Eu já escrevi 22 telenovelas, comecei muito cedo, na década de 60. Então é possível que haja uma forte dose de saudosismo da minha parte, mas eu gostaria de lembrar que nós fizemos, na década de 70 , telenovelas muito arrojadas, com uma temática muito vigorosa. Nós procurávamos até subverter as estruturas narrativas clássicas da telenovela, do folhetim, havia uma busca de linguagem. Isso foi abando-

\section{O AUTOR}

Lauro César Muniz

Dramaturgo e diretor de teatro e telenovela. nado, mas é claro que uma proposta colocada com muita força sempre permanece um tempo, até por inércia,

1 Trechos do depoimento dado pelo dramaturgo Lauro César Muniz por ocasião do evento Encontro com o Autor, ocorrido em 02/12/94, na ECA-USP, promovido pelo Núcleo de Pesquisa de Telenovela, coordenado pela Profa. Dra. Anamaria Fadul. Esclarecemos que os procedimentos adotados para a publicação deste texto foram os seguintes: o depoimento foi gravado; as fitas, transcritas, passaram por copidescagens, objetivando não só reduzir as características da oralidade, como também adequar a redação a alguns padrōes editoriais. São etapas que se consituem em verdadeiros filtros, por onde passaram os conteúdos enunciados. 
não se esvazia de imediato. Mas paulatinamente aquele grande esforço de busca de uma linguagem arrojada e de temáticas mais ambiciosas foi se esvaziando até chegarmos nos dias de hoje, em que são raras as telenovelas que têm uma proposta mais contundente.

\section{A busca de uma linguagem arrojada e de temáticas vigorosas foram os objetivos perseguidos pelos autores na década de 70 para tornar a telenovela uma manifestação de comunicação artística}

Eu me lembro de títulos como O Bem-Amado de Dias Gomes, Os Ossos do Barão de Jorge Andrade, O Rebu do Bráulio Pedroso, Grabriela de Jorge Amado, com adaptação muito feliz de Walter George Durst. Mesmo no final da década de 60, o Beto Rockfeller deu uma contribuição fantástica para a linguagem da telenovela em busca de uma linguagem brasileira. Eu incluiria também trabalhos meus como Escalada, O Casarão, Espelho Mágico.

A partir das telenovelas que eu citei, esperava-se encontrar hoje uma linguagem melhor estruturada, uma linguagem que buscasse uma certa preocupação artística. Isso infelizmente não aconteceu. $\mathrm{Na}$ década de 80 podemos pegar aqui e ali algumas telenovelas que me parece - na inércia desse movimento da década de 70 - ainda conseguiram estabelecer uma comunicação com preocupações artísticas. Mas, depois, sobretudo nesta década de 90, a coisa se esvaziou a um tal nível que é preocupante para mim, que construí toda a minha vida na televisão, na telenovela. É triste sentir que o gênero está se esvaindo, as ambições temáticas estão se perdendo...

Por que isso aconteceu? Alguns fatores me parece que são importantes considerar, por exemplo, a entrada da TV a Cabo, ou a ampliação das possibilidades de locação de filmes em videolocadoras.

Um determinado tipo de público mais exigente transferiu-se da televisão para o videocassete: ao invés de assistir às emissoras que têm uma programação normal, esse tipo de público prefere o videocassete. E, começando a crescer agora, a TV por Assinatura, por antenas parabólicas ou a cabo, sem dúvida estão desviando telespectadores das grandes redes. O público da TV a Cabo e do videocassete é um telespectador de nível social superior, em geral mais exigente.

$O$ fato de as emissoras de televisão estarem dirigidas a um público que não tem acesso à $T V$ por Assinatura e ao videocassete, faz com que os que decidem o nível da programação tenham sido tentados a baixá-lo um pouco, buscando uma comunicação imediata através da linguagem mais simples do melodrama, do folhetim, daquilo que é esquemático, do maniqueísmo. Exatamente as coisas que nós estávamos evitando na década de 70 e em parte da década de 80. 
Nós éramos um grupo de autores decididos a renovar a linguagem e fazer da telenovela brasileira um gênero artístico de uma certa importância. Tínhamos essa ambição.

Havia no ar um clima de busca de uma linguagem vigorosa, uma linguagem mais ambiciosa. Isso se perdeu, e é nítido. E quando as emissoras começam a se preocupar em fazer novelas muito mais antigas, novelas de outras épocas, novelas até da década de 60 , novelas de rádio, me parece um sintoma de que estamos mesmo buscando uma linguagem mais elementar, uma linguagem de comunicação mais fácil.

Em 1993, eu participei de um desses projetos que se chamava Sonho meu, é um remake, uma adaptação de duas novelas do Teixeira Filho que nunca foram consideradas novelas importantes, a não ser pelo fator de comunicação fácil. Era uma novela muito simples, uma novela maniqueísta, absolutamente calcada nos mitos de contos de fada. Não abria mão nem dos sonhos da criança, nem do velhinho bondoso que fazia brinquedos, uma espécie de Gepeto. Havia até uma Cinderela meio estranha, um tipo de Cinderela.

Para atender uma filosofia atual da emissora, fiz uma telenovela que não tem nada a ver com aquela linguagem da década de 70 . Então, também sou cúmplice do que está acontecendo. Os irmãos Coragem, de Janete Clair, é outro exemplo de remake de telenovela da década de 70. Foi feito por um grupo de autores, que deram uma contribuição fundamental para a história da telenovela. E assim estamos nós todos fazendo esses remakes, é uma contingência do momento e espero que seja apenas um momento.

\section{As telenovelas perderam qualidade em relação à produção das décadas de 70 e 80 , mas ainda continuam sendo vitais para o público brasileiro}

Ao analisar e ver todas as novelas que eu fiz, é muito difícil estabelecer um denominador comum, ou seja, uma temática comum a todas as novelas. Isso em telenovelas é uma coisa muito difícil. É pouco provável que alguém tenha uma temática pré-planejada, como por exemplo, a temática de alguns autores no teatro ou no cinema, onde o diretor tem uma visão global da sua obra. Na telenovela o autor, muitas vezes, é despersonalizado porque trabalha em função do processo. É difícil o autor planejar, ter um trabalho autoral.

Existem algumas tentativas, eu tenho trabalhos, nos quais vejo alguma coerência. Se eu ligasse Os deuses estão mortos, uma novela que fiz na TV Record, com Escalada e O Casarão, eu poderia dizer até com uma certa arrogância que fiz uma trilogia, na qual a preocupação era a ascensão das classes sociais, a modificação, cada uma a seu tempo, das classes que dominavam o espectro social do país. Eu poderia fazer essa relação a partir de três novelas, mas não fiz três apenas, eu fiz mais de vinte, então é muito difícil estabelecer uma temática comum a todas elas. 
As novelas que fiz na década de 80 , como por exemplo, Transas e caretas e Um sonho a mais foram novelas de nítida concessão, trabalhos que atenderam ao processo mercadológico do momento, à filosofia de um determinado horário da emissora. Procurei fazê-las dentro do meu universo temático, mas é claro que me fugia muito a possibilidade de controle. Há, no entanto, novelas da década de 80 , nas quais retomei essa preocupação mais políticosocial como em Roda de Fogo, ou em O Salvador da Pátria, que foi uma novela extremamente difícil de levar até o fim, por uma questão até de calendário. A novela estreou no ano em que se elegia o primeiro presidente do Brasil, depois de 25 anos de ditadura. Esta foi uma novela que sofreu todas as consequiências de estar num ano muito especial, de eleição para Presidente da República.

Esse projeto se frustrou. Acredito que ele poderia até ser levado às últimas conseqüências se eu tivesse escrito essa novela em outra época.

Outras novelas muito importantes foram feitas antes, como Vale Tudo, do Gilberto Braga, ou mesmo Roda de Fogo, uma novela bastante contundente. Nela se falava pela primeira vez, num meio de comunicação de massa, da tortura, pela primeira vez numa ficção de televisão o assunto foi tratado.

No teatro, Dias Gomes abordou o tema na peça Campeões do Mundo. Eu havia abordado esta temática na peça Sinal de Vida, mas sempre de um modo muito sutil. Em Roda de Fogo foi possível abordar de uma maneira mais contundente e sem metáforas a relação entre um torturador e a torturada, a vítima da tortura. Isso foi feito de forma muito forte e incisiva. Havia ainda nessa ocasião a censura oficial que só foi derrubada com a promulgação, em 1988, da nova Constituição.

Hoje as telenovelas estão mais preocupadas com a inter-relação do vilão e sua vítima, do herói contra o vilão. Algumas novelas recentes esboçaram uma análise do país, novelas que tinham inicialmente uma tentativa de fazer um levantamento do buraco em que esse país se encontra, mas a temática social também se esvaziou, dando lugar apenas às relações melodramáticas de seus personagens.

É o sinal dos tempos? Eu estou defasado? Em que estou errado? Eu sou anacrônico? Sou ingênuo? Eu não sei. Eu me pergunto muito sobre isso.

Hoje não há censura, pelo menos censura oficial. Existe uma censura sutil das emissoras, ou talvez um código de ética, ou até, vamos dizer, uma filosofia política, moral e de costumes, mas é muito sutil. Mesmo dentro da televisão, com as minisséries, nós podemos desenvolver um trabalho mais contundente. A minissérie é veiculada num horário mais avançado, há uma grande tolerância com relação a elas, não há uma censura rigorosa, nem sutil, nada. 


\section{A telenovela brasileira é um produto diferenciado, entre outros fatores, devido ao fato de alguns diretores de cinema, autores e atores de teatro terem feito da ficção televisiva seu meio de expressão durante o período de ditadura militar}

Outros canais de comunicação se abriram para os autores, e com isso é possível que a telenovela tenha se ressentido. Nós não temos mais aquela necessidade de fazer nossa palavra sobreviver a partir da telenovela. Naquela época, é verdade, no fim da década de 60 , e no início da década de 70 , não havia a menor possibilidade de encenarmos nossas peças de teatro, a não ser aquelas que fossem muito simples, comedinhas de triângulo amoroso. No início da década de 70, nós nos lançamos com muita voracidade na telenovela, buscando como comunicar alguma coisa, mesmo por metáfora. Conseguimos transformar o Brasil em pequenas cidades do interior e, à guisa de falar das pequenas cidades, falarmos do país. Nós conseguimos aqui e ali driblar a censura de uma maneira muito hábil.

Em Escalada, por exemplo, eu queria falar da construção da cidade de Brasília, queria fazer uma homenagem ao Juscelino Kubitschek, mas não tinha condições para fazer isto, sequer para citar o nome do Juscelino na novela. No entanto, sutilmente, consegui, em plena ditadura, passar a idéia de que houve no Brasil um presidente bem sucedido dentro de um processo democrático. Foi possível dizer isso: um presidente que construiu, renovou o país, dentro dos processos constitucionais, dentro do processo democrático. Em O Casarão, muita coisa foi possível dizer, não só em termos políticos, como em relação aos costumes. Tratamos da emancipação feminina através de várias gerações da mesma família, de várias personagens femininas. Em Escalada discutimos o divórcio, tema tabu na época.

Gabriela é outro exemplo. Esta novela trabalhou uma visão de mulher bastante positiva, e até certo ponto revolucionária para aquele momento. As novelas satíricas do Dias Gomes, falando de ecologia, falando dos espigões, da exploração imobiliária, no fundo eram uma forma de falar do poder. Fizemos todas essas coisas e o nosso canal era a telenovela, e isso talvez tenha sido muito bom para ela, um fator positivo. Hoje nós não temos essa preocupação. Se não podemos comunicar através da telenovela toda nossa angústia, vamos para o teatro e fazemos nossas peças, ou vamos para o cinema, ou para as minisséries.

São muitos, portanto, os fatores, além do nascimento do videocassete e do aparecimento da TV por assinatura, da existência ou não da censura, que interferem na qualidade da telenovela. 
Eu só espero que isso não mate o que a telenovela tem de melhor no Brasil. Porque, apesar de todos os problemas que temos, nós fazemos uma telenovela ainda muito importante, mesmo com toda a perda de qualidade. Fazemos uma telenovela muito superior ao que a gente vê na média dos outros países.

Superior à novela que se faz no México; ou que se faz nos Estados Unidos - a soap opera; ou à telenovela que se faz no Chile, por exemplo. Eles, de certa forma, perseguem os nossos caminhos. No Chile existe um processo de censura muito rigoroso, a ponto de exibirem o Renascer à meia-noite. Eles exibiram o Salvador da Pátria em horário normal, depois passaram para a meia-noite, porque foi considerada uma novela extremamente fora dos padrões dos costumes chilenos. Eles estão produzindo as novelas que nós exibimos no horário das sete ou novelas muito antigas, como o Coração Alado de Janete Clair. Eles vão apresentar agora Estúpido Cupido do Mário Prata. Puseram no ar a minha novela Transas e Caretas e compraram Escalada, mas ainda não se decidiram a produzi-la. Também compraram $\mathbf{O}$ Bem-Amado, mas está também na gaveta.

Comparativamente é melhor o nosso processo de trabalho do que o dos chilenos. Eles ainda têm o cacoete da ditadura. As pessoas ainda falam baixinho nos restaurantes quando têm que falar sobre qualquer assunto de política. Elas falam em tom baixo como nós fazíamos nas décadas de 70 e de 80 . Nós tínhamos medo, nos restaurantes olhavámos se na mesa ao lado não havia uma escuta, uma coisa desse tipo.

Também temos muito mais jogo de cintura do que eles. Por que estou falando deles? para mostrar como é vital a nossa telenovela, já que eu senti isso na pele, durante minha permanência lá, dando um curso para um grupo de autores de televisão.

Quando fiz Escalada estava marcado politicamente, mas eu me virava para me liberar e a emissora estava do meu lado, me dava todas as condições de ir a Brasília e liberar as cenas que eles cortavam. Eu ia e discutia com os censores e fazia um jogo de acertos com eles. Isso nós fazíamos: se concedia aqui para liberar ali.

Consegui liberar um Caso Especial que estava proibido, $\mathbf{O}$ Crime do Zé Bigorna. Não havia a menor possibilidade de produzi-lo. Eu fui dialogar com os censores para ver até que ponto eu podia ir, tinha que ser flexível para poder encenar o trabalho.

Esse tipo de luta nós fizemos, essa maleabilidade, esse jogo de cintura nós tivemos porque nós sabíamos o quanto era importante comunicar algo para a grande massa que estava vivendo absolutamente fechada no processo ditatorial. Essa flexibilidade nós tínhamos e os chilenos não têm. Por quê? Não sei. Temos mais jogo de cintura, talvez. O processo ditatorial deles foi mais forte do que o 
nosso? Veja, os mexicanos não tiveram recentemente nenhum processo ditatorial explícito. De certa forma, a televisão trabalha sem censura e, no entanto, eles não se arrojam a fazer um trabalho mais contundente. É sempre aquele melodrama, aquelas propostas muito simplificadas.

Eu não sei porque mas nós temos alguma coisa a mais. Talvez o fato de alguns autores do teatro terem se transferido para a televisão e também os atores e diretores de cinema. Isso deve ser um fator a considerar para que nós tenhamos feito uma telenovela um pouco mais criativa, interessante.

\section{Diferentemente da peça de teatro e do roteiro de cinema, a telenovela é, desde a concepção dos primeiros capítulos, uma produção completamente industrial}

Estima-se que uma telenovela das $20 \mathrm{~h}$ seja vista hoje no auge de sua audiência, ou seja, no final, até por 50 milhões de telespectadores, o que é realmente um universo fantástico. Não acredito que, no mundo de hoje, haja alguma outra coisa que se comunique assim, com essa força. Talvez na China, não sei...

Isso cria no autor uma consciência de responsabilidade muito grande. Mesmo no momento mais difícil, durante O Salvador da Pátria, eu me questionava: "Será que eu tenho o direito de fazer essa pregação?". Por mais dialético que eu fosse, por mais que expusesse com clareza meus pontos de vista, será que eu tinha o direito de fazer aquilo? Eu me questionava muitas vezes. Eu sentia o meu poder.

Mas também tem um lado positivo nisso. Por exemplo, em $\mathbf{O}$ Casarão eu tinha segurança absoluta que ao falar da emancipação feminina estava mesmo prestando um serviço. Essa angústia que eu tinha no Salvador da Pátria, eu não tinha quando eu falava da emancipação feminina em $\mathbf{O}$ Casarão - a oportunidade de possibilitar a tomada de consciência a um amplo segmento da sociedade e falar sobre a importância de a mulher ter consciência de si mesma e consciência dela na sociedade. Era muito gratificante. Em $\mathbf{O}$ Salvador da Pátria eu tinha essa angústia, essa dúvida; e no Casarão eu não tinha. É uma questão de temática, porque ali estava em jogo um ano eleitoral, estava em jogo a eleição de um presidente, estava em jogo o rumo que o país ia tomar e eu me achava absolutamente pequeno, eu não me julgava com o direito de influenciar de forma maciça numa questão tão importante.

A TV nos coloca ainda diante de uma outra questão, a que se refere à produção. Quando vou escrever uma peça de teatro, quando vou fazer um roteiro de cinema, a temática é absolutamente pessoal, é minha, faço o que eu quiser. Não tenho um elenco definido, não tenho uma produção definida, não tenho compromisso com ninguém a não ser comigo mesmo. Eu vou me isolar e escre- 
ver uma peça de teatro. Geralmente, são aquelas coisas compulsivas: o autor já não agüenta mais ficar sem falar sobre determinado assunto. E uma idéia que nasce e que vem se armando durante muito tempo. Um dia eu digo: "Agora está na hora de escrever sobre isso", e coloco no papel, solitariamente, sem preocupação para quem eu estou falando. Se a platéia quiser ela virá me ouvir no teatro. Quando alguém me encomenda uma telenovela é uma relação muito diferente.

No processo industrial da telenovela eu tenho que considerar qual é o tema que interessa para essa enorme platéia. Não é aquele tema que compulsivamente eu gostaria de manifestar, mas é o tema que possa interessar a essa platéia tão ampla e eclética, porque ela não virá a mim, ela estará lá e eu tenho que ir até ela. Eu tenho que atender às necessidades dessa platéia. $O$ ponto de partida é outro.

Se a Rede Globo me chama e me diz: "Você vai escrever a próxima novela das oito", eu começo a pensar o que interessa nesse momento para o país, para a nossa sociedade. Preciso estar atento à realidade mais imediata do meu país ou dos meus telespectadores, pensar nesses 50 milhões de telespectadores. Eu preciso estar atento e saber o que eles estão interessados em ouvir e discutir no momento.

O Gilberto Braga deve ter tido essa dúvida na hora em que disseram: "você vai escrever a próxima novela das oito", ele deve ter pensado sobre o que interessava falar para o povo naquele momento, e ele deve ter concluído que interessava falar sobre o Brasil, ou seja, o Brasil é viável ou não é viável? O Brasil é um caso perdido? Ou o Brasil tem saída? É um labirinto? Com saída ou sem saída? estou me valendo do exemplo de Pátria Minha.

Além disso há que se considerar a exportação, ou seja, ao mesmo tempo que eu tenho que me preocupar com o telespectador médio, eu tenho que me preocupar com o fato de que o produto vai sair do país, e para isso deve ter uma temática universal. Não posso falar de uma coisa absolutamente fechada, o tema tem que transcender, porque a novela vai ser vista no mundo inteiro. São 120 países que compram essas novelas, o que exige uma certa universalidade. Se bem que, de certa forma, uma coisa está ligada à outra, no momento em que você fala de um povo tão fantástico como é o do Brasil, um país continente como é o Brasil, onde o espectro é muito amplo, você está de certa forma falando para o mundo. Mas essa preocupação existe.

Temos que nos comunicar em função das necessidades do momento. Além do que há sempre fatores externos que acabam nos conduzindo ao armarmos uma trama ou escolhermos um tema. Você sabe que um determinado ator está ocupado, por exemplo, e você 
não pode contar com ele. Se você criar uma personagem com as características daquele ator, vai ter problemas. Por outro lado você sabe que há outro ator precisando fazer novela agora, a emissora tem interesse que ele faça. Dessa forma, se você conceber uma personagem para aquele ator ou para aquele grupo de atores, vai ser muito bom, atende às necessidades de funcionabilidade da própria emissora. Essas coisas limitam também. Olhar a realidade do país num determinado momento; buscar a temática que o povo quer discutir, ou quer ver; e servir às necessidades de funcionamento da própria emissora, isso tudo acaba pesando no processo de criação da telenovela.

Finalmente, faço uma sinopse de umas vinte páginas, na qual eu coloco o ponto de partida da história, mas dificilmente consigo definir o meio e o fim, porque uma novela é um longo processo, é um processo de 180 capítulos. A sinopse é apenas o ponto de partida.

Nos primeiros 20 capítulos eu não tenho claramente o rosto dos atores, a novela ainda não está escalada, depois e aos poucos a novela começa a ter corpo. A partir daí a coisa começa a ser mais industrial, o processo já começa a ficar mais restrito aos elementos que eu tenho. Eu já sei que posso usar tantas locações externas, eu posso ir em tais lugares para fazer as minhas cenas etc.

No teatro, no momento em que eu escolho o cenário, escolho as personagens, eu não estou comprometido com nada, eu estou livre, eu crio o que eu quiser. Na telenovela não, eu já estou amarrado àquela produção armada, eu já estou amarrado àqueles números de locações externas, já estou comprometido com aquele elenco escolhido.

Depois que a novela vai para o ar o trabalho fica ainda mais específico. Há um salto qualitativo no processo de trabalho, que é o seguinte: eu já escrevi 20 capítulos, quando eu for escrever o $21^{\circ}$, a novela já estreou; eu já assisti ao primeiro capítulo; eu já vi a novela corporificada; eu já ouvi a trilha sonora; já senti a linha da direção; já li - no dia seguinte - a primeira crítica da imprensa; o vizinho já disse alguma coisa; já desci o elevador com a empregada do vizinho, ela disse: "Aquela novela do senhor, seu Lauro, aquela personagem, aquela moça da novela era esquisita, não é?" aquilo já influenciou. Todo esse processo, esse feedback vem muito forte a partir da exibição dos primeiros capítulos. Tudo aquilo que estava armado de uma forma quase idealizada, aos poucos vai tomando corpo.

E aí começa um processo no qual você não escreve mais sozinho, você escreve com feedback permanente. É a influência da audiência, ou dos números baixos. Você não quer ter audiência baixa; então você começa a ver o que funciona e o que não funciona. O comentário das pessoas é muito forte: o público é seu co-autor. 
Por volta do capítulo 30 se faz uma avaliação: uma reunião com telespectadores típicos daquele horário; nós assistimos a essa reunião atrás de um espelho disfarçado - espelho para os que estão participando da reunião, para nós não é um espelho, é uma vitrina como a da polícia. Às vezes, em vez do espelho, assistimos à reunião por um monitor de televisão.

Nós ouvimos os telespectadores, um grupo de 12 a 15 pessoas falando claramente, criticamente sobre a nossa novela. Assistimos e aquilo nos influencia inevitavelmente. $\mathrm{O}$ processo não é mais solitário e, além disso, hoje nós dividimos todo o trabalho com colaboradores que nos dão idéias, subsídios para a trama continuar. $\mathrm{O}$ trabalho vai começando a ficar menos autoral e vai ficando mais coletivo. Coletivo porque tem colaboradores, tem feedback da imprensa, tem o feedback dos telespectadores e às vezes o silêncio. Essa é a pior crítica: o silêncio.

Isso tudo vai criando um processo industrial de trabalho, não é mais autoral. Esse processo foi autoral na nascente e depois foi se esvaziando, foi se diluindo em alguma coisa que serve à indústria. Isso não acontecia muito no passado e esta talvez seja outra das razões de uma qualidade maior das novelas da década de 70, quando elas eram mais autorais.

Eu escrevi Escalada, O Casarão, Espelho Mágico, Os Gigantes e mesmo novelas menos ambiciosas como Carinhoso e Corrida do Ouro - eu as escrevi sozinho. Era um trabalho solitário, terrível. Terrível porque me esgotava, eu ficava doente, sempre terminava a novela doente. Logo depois do Espelho Mágico eu tive um pirepaque no coração, acabei fazendo um cateterismo, tive até um pequeno infarto. Então essas coisas todas na década de 70 eram mais autorais, o processo era também coletivo, mas não existia esse grande aparato, a imprensa era mais distante, hoje a imprensa é voraz em cima de uma telenovela.

Existem revistas e colunas de jornais que o dia inteiro só falam nisso. Tudo é motivo para reportagens, estamos sempre no foco da questão. O que aconteceu com o Gilberto Braga, em Pátria Minha, é um exemplo. Uma organização de direitos dos negros atacou a novela considerando-a racista, o que foi um absurdo. Ao contrário, o Gilberto fez uma coisa para defender os negros e, no entanto, eles estão vendo por outro ângulo, eles não estão percebendo que o esquema do Gilberto conduzia à emancipação, ou seja, pelo menos à denúncia da existência da discriminação, do vilão branco contra um grupo de negros. É tão claro que o Gilberto quis defender os negros, mas para criar a celeuma, a imprensa atiçou essa discussão. 